\title{
Discussions on Experiment Teaching of Mechanical System Dynamics
}

\author{
Xin-ju Zhang \\ Collage of Mechanical Engineering, Hebei University of Science and Technology, Hebei \\ Shijiazhuang 050018, CHina \\ zhangxinju2010@163.com
}

Keywords: Mechanical system dynamics, Experiment teaching, Teaching step, Teaching method, Educational reform.

\begin{abstract}
As a theoretical and practical basic technical course for the students in the specialty of mechanics, mechanical system dynamics is one of the primary courses to train professional technical talent. In the meantime, experiment teaching of mechanical system dynamics is an important channel for undergraduate students to acquire basic experimental skills and develop scientific literacy. The design thought and experiment contents by combining the latest achievements in scientific research are discussed according to strong practicality of the course. In order to develop students' ability of self-educated and practice, some research on how to reform the teaching has been made, and some measures to improve experiment teaching have been put forward in this article. In practice, the reform of experimental teaching has improved the overall quality of instruction effectively.
\end{abstract}

\section{Introduction}

The course of the Mechanical system dynamics is one of the important basic courses of various kinds of machinery subjects and is a course in project utility strongly. The course can help the students improve their abilities to analyze and resolve problems, and prepare their future research \& develop work related with mechanism designing. Experimental practice is an important part in the course of the Mechanical system dynamics. By the practice teaching, students not only comprehend the Mechanical system dynamics' theory, but also mastery the advanced experimental technology. And better teaching effect can be reached.

\section{Aim and request of the practice teaching}

The practice teaching is an important factor to realize the target of talent education, is one of the best tools to integrate theory with practice, and is one of the important paths to cultivate the students' scientific research and creative abilities. In experiment teaching of the Mechanical system dynamics, we should stress on cultivating students' learning ability, solving actual problems, and exploring and creation.

The theories and methods of the mechanical system dynamics have closely relationship with project. For example, in 1940, the Tacoma Narrows Bridge in the American state of Washington collapsed into the sea below because of resonance caused by strong winds; in 1972, a $660000 \mathrm{KW}$ turbine-generator in Japan was completely destroyed because the turbine-generator rotor had been

Project supported by the fund of the educational and teaching reform of polytechnic college of hebei university of science and technology. 
broken off; in 1958, the first U.S. satellite, Explorer 1 was out of control at high rate while it was launched into orbit; Track vibration produced an effect on the ride performance and comfort ability of the tracked vehicles; the machine tools could generate severe vibration while it was running, and accompanied by a strong noise, and so on. According to the national teaching structure of mechanics, students should do some experiments at the stage of special field of study, so, they can understand and grasp the mechanical dynamics theory better.

Self-study ability in students is one of the basic missions of higher mathematics teaching. Results more than $75 \%$ students thought that the new practice teaching mode can stimulate their capability to study. Now if our students' ability to study independently has been greatly improved, they would master some more knowledge. Only when we know well both scientific knowledge and practical skills can we live happily and work wonderfully in the society in the coming future. Meanwhile, by practice teaching, the students' ability to analyses and solve problems can be developed, and students can comprehend and verify the theory knowledge.

\section{Experimental content}

After learning college physics, higher math, machinery design, machine theory and theoretical mechanics, etc., mechanical engineering students have got some basic knowledge of mechanical system dynamics. So those students can be proactive in the experiments of the course of mechanical system dynamics, with the encouragement and help of their teachers. Routinely to be responsible to accomplish LWR independently in time, which includes experimental instruments preparing, experimental content organizing, experimental procedure analyzing and recorded data analyzing.

On the basis of the theory of pedagogic principle, the experiments of the cour5e of mechanical system dynamics can be classified into three categories: verification experiments, comprehensive and designing experiments, innovative experiments. Verification experiments are those whose results have been well-known before the experiments began. Verification experiments will help students deepen understanding the basic theory of the course. Verification experiments mainly includes the following contents: damping amplitude experiment of free-damped Vibration, vibration isolation experiment, vibration model experiment of 2 degree freedom vibrator; Of all experiments, the most vivid and active teaching method is comprehensive and design experiments, comprehensive and designing experiments mainly includes the following contents: speed regulation experiment of a mechanical system, dynamic vibration absorber experiment. Innovative experiment is not the simple verification on a certain knowledge point, but the comprehensive application of specialized knowledge. Innovative experiment mainly includes the following contents: vibration mill experiment, vibratory crusher experiment, vibrating conveyer experiment ${ }^{[1][2][3]}$.

\section{Practice teaching reform}

With the unceasingly thorough of mechanical system dynamics study, students' abilities of design and practice continues to improve. In the meanwhie, tempo of classroom instruction, scope and depth of content of courses increase the difficulty of mechanical system dynamics teaching. So we must emphasize the fact that educational purposes are to cultivate highly qualified talents expert at applied technology and to let the students from passive learning into autonomous learning, improve the students' interest in learning. During the teaching process, we should fully respect students, exert their creation, respect their individual difference and adopt individual teaching method that it can adjust to them. It is of great significance to strengthen practical teaching research, clarify the 
practical teaching objectives in theory, deepen practical teaching reform and improve practical teaching quality. Practice teaching is reformed in recent years according to the educational aim and request. The main contents as follows ${ }^{[4][5] \text { : }}$

Redistribution of experimental quantity. We have been effectively reduced the number of verification experiments, and increased the number of comprehensive and designing experiments, innovative experiments. The goal of reform is to achieve the ability to apply one's knowledge in new ways. For example, oscillator, mass, spring, damper, frequency converter, an oscilloscope, data acquisition card and a computer can be used to create an experiment platform by students. Students can quickly locate the problems and solve them quickly as well from experimental studies ${ }^{[6][7]}$.

Reform on the teaching content. By comprehensive reforms and innovation in the content of experimental teaching, our group has edited typical textbooks in our teaching practice. When some contents of the course are abstract, we have been trying different ways to introduce methods into our course. For example, while teaching the multi degrees-of-freedom model, I have developed the vibration mill experiment. Students can establish a dynamic model for the vibration mill. meanwhile, they can determined the resonance frequency of it. It enhances students' ability to design experiment and the ability of doing experiment independently and makes students understand the course more easily ${ }^{[8][9]}$.

Revolution in teaching techniques. To train high qualified talent for modern society, we must alter traditional teaching mentality in class and inspire students' participation consciousness. We advocate the innovative education to train students' ability of problems solving, so that we can make full use of students' subjective initiative of problems solving. Teacher-student interaction can change the mode of traditional cramming method of teaching so that teachers and students in the classroom teaching in a completely equal footing. Now teachers should supply students with good experimental equipment and encouragement, students could accomplish experiments by themselves.

\section{Summary}

Now we have introduced much scientific research to teaching method, largely enriching the experiment contents. In the meantime, to prove the theory of the technique, some experimental platforms have been constructed. We have a gradual shift to focus on training up students' learning ability of independent exploring and cooperating from the traditional mode of education .It has been proved in teaching practice that reform on the experiment teaching can be very efficient in developing students' ability to solve problems and leading to satisfying teaching results.

\section{References}

[1] Yixin Zhao, Yan tang, Wei Huang: submitted to Journal of Southwest China Normal University (Natural Science Edition) (2009)

[2] Boqian Zhang:submitted to journal of study on laboratory work in university (2003)

[3] Xuhua Shi, Haizhen Yu: submittied to journalof Research and Exploration in Laboratory 
[4] Xiangfeng Zhang:submittied to journalof Research and Exploration in Laboratory (2014)

[5] Fengkui Duan, Gang Yu, Jun Huang, etc.:submittied to journalof Research and Exploration in Laboratory (2014)

[6] Xinhuo Wen, Yingzi Guo, Jing Wei:submitted to journal of experimental technique and management (2010)

[7] Xigui Zhu, Xiaoping Peng, Jiahe Jin: submittied to journalof Research and Exploration in Laboratory (2004)

[8] Yanxia Sun:submittied to journalof Research and Exploration in Laboratory (2005)

[9] Weida $\mathrm{Pu}$, Haiquan $\mathrm{Wu}, \mathrm{Hu}$ Huang:submittied to journalof Research and Exploration in Laboratory (2002) 